\title{
Karakterisasi Sifat Fisik dan Sifat Mekanik Komposit Polyurethane/Serbuk Bambu Sebagai Aplikasi Panel Pintu Mobil
}

\author{
Siti Komariyah, Moh. Farid dan Amaliya Rasyida \\ Jurusan Teknik Material dan Metalurgi, Fakultas Teknologi Industri, \\ Institut Teknologi Sepuluh Nopember (ITS) \\ Jl. Arief Rahman Hakim, Surabaya 60111 Indonesia \\ e-mail: mofaredo@gmail.com
}

\begin{abstract}
Abstrak-Panel pintu merupakan bagian badan mobil yang pada umumnya terbuat dari material termoplastik dengan kekuatan lentur antara 11-25 MPa. Akan tetapi, sejak tahun 2015, European Union's end-of-live of Vehicles (ELV) menekankan untuk menggunakan material daur ulang, yang menjadikan penambahan serat natural pada beberapa badan mobil sebagai trend terbaru. Penelitian ini bertujuan untuk mensintesis komposit polyurethane/serbuk bambu (PU-SB) sebagai material kandidat panel pintu mobil dan mengetahui pengaruh penambahan serbuk bambu pada komposit PU-SB. Bahan utama pembentuk komposit terdiri dari polyurethane dan serbuk bambu betung berukuran $<140 \mu \mathrm{m}$. Metode yang digunakan dalam pembuatan komposit adalah metode blending dengan variasi komposisi serbuk bambu 5\%; 10\%; dan $15 \%$ fraksi massa komposit. Untuk mencapai tujuan tersebut, dilakukan analisa densitas dan analisa kekuatan lentur berdasarkan ASTM D 790. Dari penelitian ini diperoleh, komposit dengan penambahan $15 \%$ serbuk bambu memiliki nilai densitas sebesar $0.1093 \mathrm{gr} / \mathrm{cm}^{3}$ dan kekuatan lentur sebesar 28,20 MPa.
\end{abstract}

Kata kunci- Komposit, polyurethane, serbuk bambu, sifat mekanik

\section{PENDAHULUAN}

$\mathrm{S}$ ALAH satu jenis bambu yang banyak diteliti adalah jenis bambu betung (Dendrocalamus asper). Kadar air pada bambu betung mencapai 55\%, dengan kandungan holoselulosa sebesar 53\%, pentosan $19 \%$, lignin $25 \%$, abu $3 \%$ dan kelarutan dalam $\mathrm{NaOH}$ sebesar $22 \%$. Holoselulosa terdiri dari selulosa dan hemiselulosa. Kadar holoselulosa yang tinggi mengindikasi serat yang kuat. Sedang hemiselulosa yang tinggi menyebabkan sifat fleksibel. Kekuatan lentur komposit polyester berpenguat serat bambu. mencapai 26,22 $\mathrm{MPa}$ dan kekuatan tarik mencapai 15,6 MPa [1]. Selain sifat mekanik yang baik, bambu juga memiliki nilai densitas yang kecil. Densitas bambu berkisar antara 0,6-1,1 $\mathrm{gr} / \mathrm{cm}^{3}$ [2]. Kemampuan absorbsi suara komposit berpenguat bambu juga tinggi [3]-[4]. Produksi bambu di dunia mencapai 30 juta ton per tahun. Dengan nilai produksi yang besar ini dan sifat yang unggul, bambu dapat menjadi penunjang ekonomi masyarakat [5].

Salah satu bentuk pemanfaat bambu dalam bidang teknologi adalah sebagai bahan penguat dari panel pintu mobil. Panel pintu mobil merupakan bagian dari badan mobil yang terbuat dari material termoplastik dengan kekuatan lentur berkisar antara 11 hingga $25 \mathrm{MPa}$ dan kekuatan tarik berkisar antara 30 hingga $95 \mathrm{MPa}$. Panel pintu mobil pada umumnya terbuat dari polipropilen, polyester atau polyurethane (PU). Akan tetapi, sejak tahun 2015, European
Union's end-of-live of Vehicles (ELV) menekankan untuk menggunakan material daur ulang, yang menjadikan penambahan serat natural pada beberapa body mobil sebagai trend terbaru [6].

Polyurethane (PU) terbentuk dari reaksi antara polyol dengan diisocyanate. PU memiliki kelebihan seperti tahan terhadap air dan tahan bahan kimia, tahan gesek juga tahan terhadap cuaca. Akan tetapi, PU juga memiliki kekurangan seperti stabilitas termal dan kekuatan mekanik yang rendah [7]. PU merupakan salah satu material utama panel pintu mobil. Sebagai salah satu bahan pembentuk panel pintu mobil, nanomaterial dipilih sebagai penguat komposit PU. Pada penelitian ini, akan dilakukan pengembangan material komposit polyurethane berpenguat serbuk bambu. Melalui analisa densitas dan analisa kekuatan lentur dari komposit polyurethane dengan variasi komposisi serbuk bambu, diharapkan dapat diperoleh material kandidat sebagai aplikasi panel pintu mobil.

\section{METODOLOGI PENELITIAN}

\section{A. Persiapan Bahan dan Alat}

Bahan yang digunakan dalam penelitian ini terdiri dari bambu betung dan polyurethane. Bambu betung yang digunakan berdiameter $10 \mathrm{~cm}$. Pengolahan bambu betung diawali dengan penghancuran bambu secara makro, kemudian dilakukan perendaman dalam $\mathrm{NaOH} 5 \%$ selama 24 jam untuk menghilangkan kandungan lignin yang terdapat pada bambu. Bambu kemudian dicuci bersih dengan air, lalu jemur dibawah sinar matahari langsung. Untuk hasil lebih baik, bambu yang telah berbenrtuk serat kasar dikeringkan kembali menggunakan oven dengan temperatur $250^{\circ} \mathrm{C}$ selama 2x10 menit. Setelah itu, serat bambu dipotong sepanjang 1 $\mathrm{cm}$ untuk mempermudah proses pencacahan. Serat bambu kemudian dicacah menggunakan blender hingga halus. Serat yang telah halus selanjutnya melalui proses sieving. Hasil akhir bambu yang digunakan dalam penelitian ini berupa serbuk berukuran $<140 \mu \mathrm{m}$.

Bahan pembentuk PU terdiri dari polyphenyl isocyanate dan polyprophylene glycol. $P U$ dibuat dengan mencampurkan Polyphenyl isocyanate dan Polypropylene glycol. Komposisi yang digunakan dalam pembuatan komposit ini adalah $70 \%$ untuk Polyphenyl isocyanate dan $30 \%$ untuk Polypropylene glycol.

\section{B. Pembuatan Komposit}

Pada penelitian ini, digunakan variasi komposisi serbuk bambu sebesar 5\%; 10\%; dan 15\% fraksi massa komposit. Sedang komposisi pembentuk PU, yakni terdiri dari 
Polyphenyl isocyanate dan Polypropylene glycol dengan perbandingam 70 : 30 fraksi massa matrik. Pembuatan komposit menggunakan metode blending. Komposisi masing-masing spesimen ditunjukkan pada Tabel 1 sebagai berikut.

Tabel 1

Komposisi Polyurethane dan serbuk bambu

\begin{tabular}{ccc}
\hline \hline Spesimen & $\begin{array}{c}\text { Komposisi PU } \\
(\%)\end{array}$ & $\begin{array}{c}\text { Komposisi } \\
\text { Serbuk } \\
\text { Bambu }(\%)\end{array}$ \\
\hline 85\%PU-SB & 85 & 15 \\
$90 \%$ PU-SB & 90 & 10 \\
$95 \%$ PU-SB & 95 & 5 \\
\hline \hline
\end{tabular}

PU dan serbuk bambu ditimbang sesuai dengan komposisi. Total massa kedua bahan tersebut perspesimen adalah $25 \mathrm{gr}$ untuk spesimen densitas dan 20 gr untuk spesimen uji lentur. Setelah itu, kedua bahan dicampur dan diaduk secara merata. Bahan kemudian di tuang dan didiamkan selama 24 jam. Setelah 24 jam, komposit dikeluarkan dari cetakan dan dipotong sesuai dengan standar pengujian. Spesimen uji kekuatan lentur berukuran $127 \mathrm{~mm}$ x 12,7 mm x 3,2 mm berdasarkan ASTM D 790. Spesimen densitas berbentuk bulat dengan diameter $100 \mathrm{~mm}$ dan tebal $25 \mathrm{~mm}$.

\section{Uji Karakterisasi Perhitungan Densitas Komposit}

Analisa bertujuan untuk mengetahui massa jenis dari komposit. Analisa densitas ( $\rho$ ) dilakukan dengan menghitung hasil bagi dari massa komposit (m) dan volum komposit (V), menggunakan persamaan berikut.

$$
\rho=\mathrm{m} / \mathrm{V}
$$

\section{Pengujian Kekuatan Lentur}

Analisa kekuatan lentur bertujuan untuk mengetahui kekakuan material ketika dibengkokkan. Analisa kekuatan lentur dilakukan berdasarkan ASTM D 790 dengan metode three point bend, dimana spesimen diletakkan pada dua tumpuan, dan beban diberikan ditengah spesimen. Spesimen yang digunakan berukuran $127 \mathrm{~mm}$ x 12,7 mm x 3,2 mm. Perhitungan kekuatan lentur, dilakukan dengan persamaan sebagai berikut.

$$
\sigma_{\mathrm{f}}=\left(3 \mathrm{PL} / 2 \mathrm{bd}^{2}\right)\left[1+6(\mathrm{D} / \mathrm{L})^{2}-4(\mathrm{~d} / \mathrm{L})(\mathrm{D} / \mathrm{L})\right]
$$

dimana :

of : kekuatan lentur komposit (MPa)

$\mathrm{P}$ : beban patah $(\mathrm{N})$

$\mathrm{L}:$ support span $(\mathrm{mm})$

$\mathrm{b}:$ lebar spesimen $(\mathrm{mm})$

$\mathrm{d}$ : tebal spesimen $(\mathrm{mm})$

$\mathrm{D}:$ defleksi $(\mathrm{mm})$

\section{HASIL DAN DISKUSI}

\section{A. Analisa Densitas Komposit}

Analisa densitas berkaitan dengan sifat mekanik komposit. Dari perhitungan massa dibagi volum komposit, diperoleh hasil sebagai berikut.
Tabel 2

Hasil perhitungan densitas komposit PU-SB

\begin{tabular}{cccc}
\hline \hline No. & Komposit & $\begin{array}{c}\text { Massa Jenis } \\
\left(\mathrm{gr} / \mathrm{cm}^{3}\right)\end{array}$ & $\begin{array}{c}\text { Massa Jenis } \\
\text { Rata-rata } \\
\left(\mathrm{gr} / \mathrm{cm}^{3}\right)\end{array}$ \\
\hline 1. & $85 \%$ PU-SB & 0.0494 & 0.1093 \\
& & 0.0471 & \\
2. & $90 \%$ PU-SB & 0.0386 & 0.0932 \\
& & 0.0413 & \\
3. & $95 \%$ PU-SB & 0.0377 & 0.0729 \\
& & 0.02948 & \\
\hline \hline
\end{tabular}

Dari Tabel 2, diketahui komposit 85\%PU-SB memiliki nilai densitas paling tinggi, yakni $0,1093 \mathrm{gr} / \mathrm{cm}^{3}$. Pada tabel tersebut, penambahan $5 \%$ serat memiliki nilai densitas sebesar $0,0729 \mathrm{gr} / \mathrm{cm}^{3}$. Pada penambahan serat sebanyak $10 \%$ dan $15 \%$, nilai densitas komposit semakin meningkat, masing-masing menjadi $0,0932 \mathrm{gr} / \mathrm{cm}^{3}$ dan 0,1093. Penambahan serat pada komposit dapat meningkatkan nilai densitas karena banyaknya serat dapat menciptakan void yang lebih banyak [8]. Tingginya nilai densitas juga berpengaruh pada ukuran sel. Grafik dari perhitungan densitas, ditunjukkan pada Gambar 1 berikut.

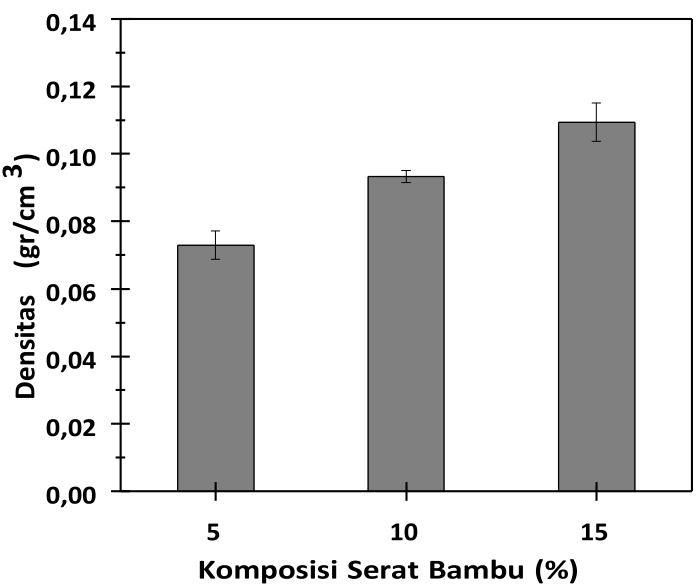

Gambar 1. Grafik densitas komposit PU-SB

\section{B. Analisa Kekuatan Lentur}

Analisa sifat mekanik bertujuan untuk mengetahui kemampuan komposit dalam menerima beban mekanik. Sebagai aplikasi panel pintu mobil, dibutuhkan kekuatan mekanik yang baik. Analisa mekanik yang dalam penelitian ini berdasarkan hasil uji kekuatan lentur komposit. Analisa kekuatan lentur bertujuan untuk mengetahui kekuatan komposit ketika dibengkokkan. Data hasil perhitungan kekuatan lentur komposit PU-SB terdapat pada Table 3 sebagai berikut.

Tabel 3

Hasil pengujian kekuatan lentur

\begin{tabular}{cc}
\hline \hline Komposit & Kekuatan Lentur ( MPa) \\
\hline $85 \%$ PU-SB & 28,20 \\
$90 \%$ PU-SB & 16,19 \\
$95 \%$ PU-SB & 13,06 \\
\hline
\end{tabular}


Dari Table 3, diketahui komposit dengan 5\% serat bambu (95\%PU-SB) memiliki kekuatan lentur paling rendah, yakni 13,06 MPa. Sedikitnya fraksi massa serat menyebabkan jarak antara serat yang jauh, sehingga kontak area antara serat dan matrik menjadi lemah, dan pengaruh serat sebagai penguat menjadi berkurang [9]. Seiring dengan penambahan komposisi serat bambu, kekuatan lentur meningkat menjadi 16,19 MPa pada komposisi serat 10\%. Dan pada komposisi serat bambu $15 \%$, kekuatan lentur komposit mencapai 28,20 MPa.

Pengujian lentur juga dilakukan pada polyurethane murni (100\%PU) sebagai pembanding. Kekuatan lentur 100\%PU mencapai 44,18 MPa. Kekuatan lentur 100\%PU lebih tinggi karena tidak adanya serat dapat menjadikan ukuran pori lebih halus dan seragam . Pori yang seragam menujukkan densitas yang tinggi dan sifat mekanik yang baik [10]. Dari seluruh pengujian lentur tersebut, maka diperoleh trend seperti Gambar 2 berikut.

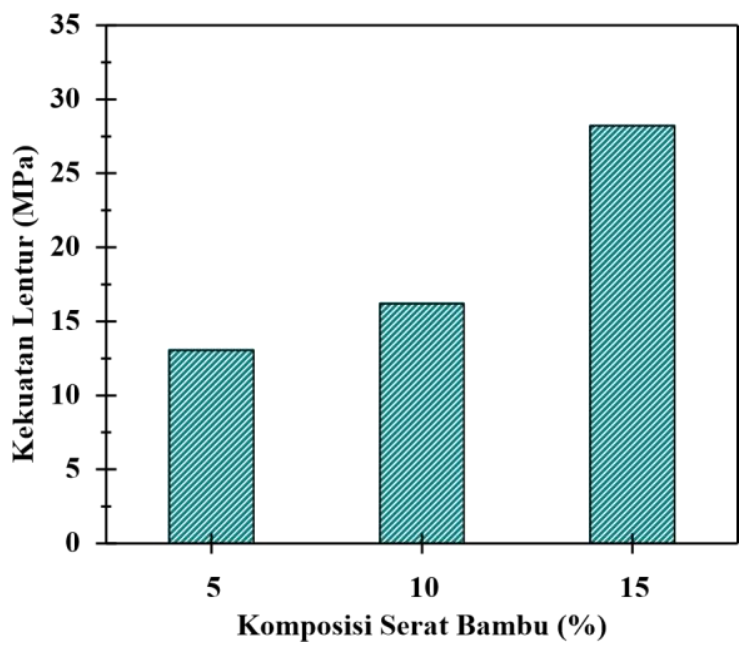

Gambar 2. Grafik nilai kekuatan lentur komposit PU-SB

Grafik pada Gambar 2 menunjukkan rendahnya kekuatan lentur pada penambahan serat 5\%. Akan tetapi kekuatan lentur terus meningkat pada komposisi $10 \%$ dan $15 \%$ persen. Nilai kekuatan lentur yang meningkat dengan bertambahnya komposisi serat dapat terjadi karena peran serat dalam distribusi pembebanan [11].

\section{KESIMPULAN}

Berdasarkan data hasil penelitian dan pembahasan, maka dapat ditarik kesimpulan bahwa penambahan serbuk bambu pada komposit PU-SB berpengaruh pada sifat fisik dan sifat mekanik komposit. Penambahan $15 \%$ serbuk bambu memiliki nilai densitas sebesar $0.1093 \mathrm{gr} / \mathrm{cm}^{3}$ dan memiliki nilai kekuatan lentur tertinggi sebesar 28,20 $\mathrm{MPa}$.

\section{UCAPAN TERIMA KASIH}

Penulis mengucapkan terima kasih kepada Program Riset Unggulan Jurusan tahun 2016 yang didanai oleh Jurusan Teknik Material dan Metalurgi FTI ITS.

\section{DAFTAR PUSTAKA}

[1] S. Sreenivasulu, A. C. Reddy, "Mechanical Properties Evalution of Bamboo Fiber Reinforced Composite Materials,"
India : International Journal of Engineering Research Volume No.3 (2014).

[2] O. Faruk, A. K. Bledzki, H. P. Fink, M. Sain, "Biocomposite Reinforced with Natural Fibers : 2000-2010," Elsevier : Progress in Polymer Science (2012).

[3] M. Farid, Heriyanto, "Correlation of Normal Incidence Sound Absorption Coefficient (NAC) and Random Incidence Sound Absorption Coefficient (RAC) of Polyester/Ramie Fibre Composite Materials," Advance Materials Research. Vol.789, (2013) (269-273).

[4] M. Farid, H. Ardhyananta, et. al, "Correlation Between Frequency and Sound Absorption Coefficient of Polymer Reinforced Natural Fiber. Advance Materials Research. Vol.1112, (2015) (329-332).

[5] H. P. S. A. Khalil, I. U. H. Bhat, M. Jawaid, A. Zaidon, D. Hermawan,

Y. S. Hadi, "Bamboo Fiber Reinforced Biocomposite : A Review," Matter Des 2012. (2012) (hal. 353-368).

[6] G. Marsh, "Next Step for Automotive Materials," Materials Today Apr 2003. (2003) (hal 36-43).

[7] K. C. Pradhan, P. L Nayak, "Synthesis and Characterization of Polyurethane Nanocomposite from Castor Oil- Hexamethylene Diisocyanate (HMDI)," Odisha : Plagia Research Library (2012).

[8] R. Gayathri, R.Vasanthakumari, "Nanomaterials in PU Foam for

Enhanced Sound Absorption at Low Frequency Region," Switzerland : Advanced Materials Research Vol. 938 (2014).

[9] L. Wang, W. Ding, Y. Sun, "Effect of Different Fiber Materials on

Mechanical Properties of Polyurethane Composites," China : 2nd International Workshop on Materials Engineering and Computer Sciences (IWMECS 2015) (2015).

[10] N. F. Acero, , "Polyurethane Foams from Renewable and Sustainable Polyols," Portugal : Instituto Superior Tecnico (2014).

[11] S. J. Kim, et. al, "Mechanical Properties of Polypropylene/Natural Fibre

Composite : Comparison of Wood Fiber and Cotton Fibre," Elsevier : Polymer Testing (2008). 